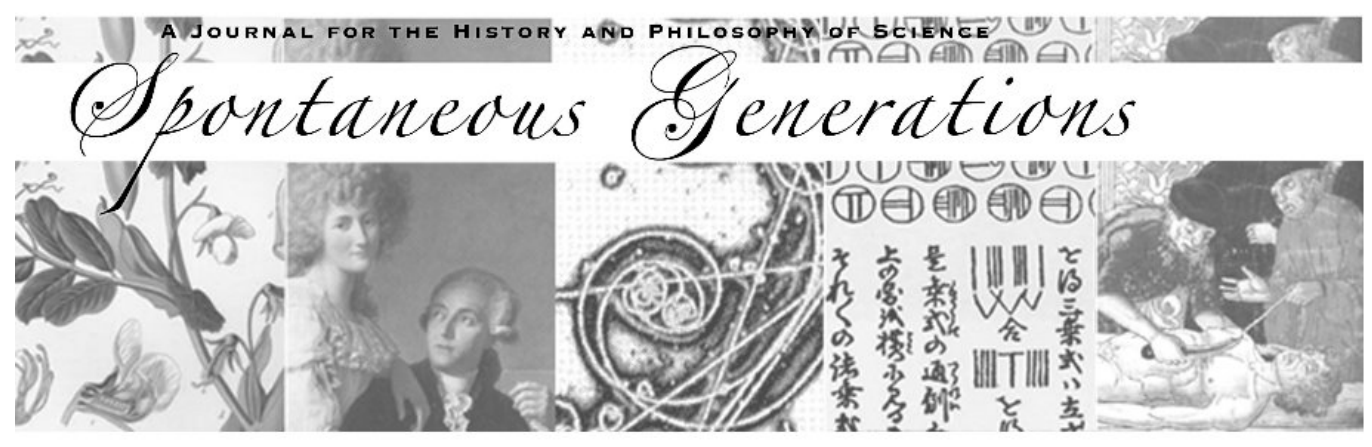

\title{
"Engineering Realities"
}

Author(s): Davis Baird

Source: Spontaneous Generations: A Journal for the History and Philosophy of Science, Vol. 4, No. 1 (2010) 94-110.

Published by: The University of Toronto

DOI: $10.4245 /$ sponge.v4i1.11332

EDITORIAL OFFICES

Institute for the History and Philosophy of Science and Technology Room 316 Victoria College, 91 Charles Street West

Toronto, Ontario, Canada M5S 1K7

hapsat.society@utoronto.ca

Published online at jps.library.utoronto.ca/index.php/SpontaneousGenerations ISSN 19130465

Founded in 2006, Spontaneous Generations is an online academic journal published by graduate students at the Institute for the History and Philosophy of Science and Technology, University of Toronto. There is no subscription or membership fee. Spontaneous Generations provides immediate open access to its content on the principle that making research freely available to the public supports a greater global exchange of knowledge. 


\title{
"Engineering Realities"*, $\dagger$
}

\author{
Davis Baird $¥$
}

\begin{abstract}
We live in a world that increasingly is designed by engineers. So it is worth asking what are engineers doing when they design. There is no simple universal answer to this question, and my strategy for answering it both acknowledges the impossibility of a simple answer, while also identifying and elaborating some important elements to engineering realities. I start with the simple posit that engineering a reality is about controlling aspects of that reality through designed artifice. I then "complexify" this simple idea by examining one company's multiple contributions to engineering realities. Ometric Corporation was birthed out of the USC NanoCenter in the fall of 2004. The company makes spectrometric equipment that allows for "real-time in-line" analysis-and control-of materials. Markets that Ometric is focusing on include pharmaceuticals, food and energy. But Ometric lives in an engineer's reality, while simultaneously working to engineer realities. It must survive financially, initially by selling the ideas behind its innovations to venture capitalists, and then by selling products to markets that may or may not currently exist. Ometric is the product of the University of South Carolina's efforts to turn its intellectual property into gold for the University. Ometric, thus, is part of a larger effort to re-engineer the University and its relationship to industry. My examination of Ometric, then, identifies some key ways that "control through designed artifice" is a complex, and yet prevalent and powerful force in the construction of our realities.
\end{abstract}

\section{INTRODUCTION}

My title equivocates between "engineering" as a verb and as part of a noun phrase. This equivocation reflects a split personality to the paper.

* This paper has benefitted from feedback from several audiences where versions of it have been presented. Thanks in particular are due to my audience at the Burian-McNabb Lecture in Science, Technology and Society at Virginia Tech. The plural in my title is due to Richard Burian's suggestion, and thanks for that.

$\dagger$ Received 22 November 2009.

$¥$ Davis Baird is Vice President for Academic Affairs and Provost and a faculty member in Philosophy at Clark University in Worcester, Massachusetts. His research concerns the role of scientific instruments in the construction of scientific knowledge. He also is co-founder of the nano Science and Technology Studies Group in the USC NanoCenter. 
I am, in the first instance, concerned with engineering as a verb, as a way we are constructing our technosphere, and with the implications for us and for the world we live in when we engineer our world. But in the second instance, engineers live in a world-an engineering reality-that has implications for how they can further intervene and for how we envision future realities-that is, how we imaginatively see a future that we move toward.

In important respects, the two readings of my title interact. How we engineer our reality is-in part-a result of the engineering reality inhabited by those building a new reality. In what follows, I consider how precision begets more precision in our increasingly engineered realities. At the same time, two other variables, cost and the "robustness" of a measurement system, interact with precision. By "robustness," I mean the ability of a measurement system to deal with variable input. The home thermometer we use to check for fever is reasonably precise, but it cannot be used to check the oven's temperature. A thermometer used for both temperature ranges would either cost more or be less precise. What follows examines the interactions or trade-offs that occur among these three variables.

I pursue this study with a paper that is half a philosophical analysis of what we do when we engineer reality and half a bit of journalism following the path of a start-up company from its conception as intellectual property through its birth as a company and forward into its efforts to survive in the market reality that engineering must face.

Ometric was birthed out of the USC NanoCenter in the fall of 2004. Ometric makes spectrometric equipment that allows for "real-time in-line" (Ometric Corporation 2008) analysis of materials. Two of the markets on which they have focussed are pharmaceuticals and food. Ometric equipment enables a kind of total quality control over drug manufacturing and processed food manufacturing-among other potential markets.

Ometric sits at the intersection of multiple ways in which we engineer our reality. My intention is to flesh out the concept of engineering reality by examining the various ways Ometric serves this end. I start with quality control itself, the purpose of Ometric's instrumentation. By comparing Ometric's approach with traditional methods of quality control, we can learn some salient lessons about control. In a nutshell, quality control requires that we identify variables we wish to control, construct metrics for measuring these variables, and establish targets for what is to count as acceptable. The rub, of course, is that it is not possible to reduce any rich portion of human reality to a small set of variables, metrics, and targets without loss. Inevitably, trade-offs result.

The distinction between a reality defined and built in response to efforts to measure and control a set small number of variables and the blooming, 
buzzing confusion that one encounters in realities less subject to human control is fundamental in the paper that follows. Efforts at engineering reality drive for more control and less variability. Yet such efforts are never entirely successful, and, furthermore, the variables used to define and exercise control will always be incomplete. Sometimes, for practical purposes, this incompleteness is of little consequence, but not always.

This much is to see the distinction between engineered reality and the less controlled "un-engineered reality" epistemologically. There is an epistemic distance between the narrow control we can achieve in any context by using a small set of variables and the broad reality we aim to control. But engineering reality is indeed about intervening, which is to say, remaking, reality. There is a metaphysical aspect to this distinction. Efforts to create a more controlled-an engineered-reality have effects. Reality is changed; it is more controlled-more engineered-and less variable.

I can provide some specific sense to this rather grand generalization in three ways. First, consider the development of precision tools. Increasing precision depends on improvements in tool design. One can chronicle these improvements over time, e.g. from early simple efforts to rule distance to highly engineered, laser-guided ruling engines. But increased precision also depends on greater homogeneity in the stock materials from which one constructs tools such as ruling engines. Precision begets better precision.

Second, consider the construction of what can be called the human technosphere: everything from central heating and cooling to water and electricity distribution and from waste disposal to communication networks. All of these systems interact: Inadequate heating leads to frozen pipes. Communication systems require electricity as do typical heating systems. Greater control in one area allows for greater control in another area and, ultimately, a more seamless technosphere.

Finally, since one of Ometric's key markets is pharmaceuticals, it is worthwhile considering what we are doing with drugs. Lessons learned about control from my discussion of quality control are instructive in understanding pharmaceutical control of human function. Here the gap between engineering reality and human reality can be highly contentious.

There is more to extract about engineering reality by digging deeper into the guts of Ometric's innovation. Ometric's instrumentation achieves its results in a manner similar to the way that a statistical technique called "principal components analysis" has been used to construct measurements of "general intelligence" from multiple tests of cognitive abilities (Baird 1992). A close examination of both the statistics used in principal components analysis and the material realization of these statistical techniques in Ometric's equipment is instructive about the 
concept of engineering reality. Here we can learn in some detail about how the gap between engineered reality and less engineered reality is a necessary feature of how we engineer reality.

To avoid misunderstanding, let me say up front that I am in no way opposed to engineering reality or doing so by various means of quality control. This is a necessary and valuable part of how we construct a better, more reliable world. I believe that the story of precision tools is a story of genuine progress. I am happy to live in a reliably heated, cooled, plumbed, and electrified home. That said, I believe it is essential that we recognize both how one goes about engineering reality and the implications of the use of such methods on the realities that ensue. We must recognize the difference between the small set of variables used to engineer reality and the richer reality they attempt to encompass.

\section{OMETRIC}

I start Ometric's story with patents filed by Professor Micky Myrick and the USC Research Foundation in 1997 (Myrick et al. 2001). These covered the basic multivariate optical approach to spectrometric analysis that Ometric instrumentation relies on, about which more below. Myrick, a professor in USC's Chemistry and Biochemistry Department, was convinced that this approach to analysis would be valuable for quality control in pharmaceutical applications. But he had difficulty persuading companies to buy into the process. Beyond these difficulties, other demands on his time curtailed his ability to move this new intellectual property out of his lab (Myrick 2004).

While Myrick was working, mostly unsuccessfully, to push his ideas for multivariate spectrometric analysis into commercial application, the University of South Carolina in July 2001 created a center for interdisciplinary work at the nanoscale. Somewhat surprisingly, one of the first, largest, and most grant-successful groups to work in USC's NanoCenter was a group of humanists, social scientists, and legal and health professionals interested in the societal and ethical interactions with nanotechnologies. One of this group's efforts was an outreach program, the South Carolina Citizens' School of Nanotechnology ( ${ }^{\text {nano }}$ Science and Technology Studies Group 2008; Toumey and Baird 2008). Over a sequence of six Wednesday evenings, school participants had the opportunity to interact with various scientists, engineers, and other academics pursuing research in nanotechnology. Jason Williamson, a young man looking for commercial opportunities in nanotechnology, was one of the first students in the Citizens' School during the spring of 2004. Here a connection was made between Williamson, Myrick, and local venture capitalist Robert Fletcher. 
During the summer of 2004, at Williamson's suggestion, Myrick gave a presentation on multivariate optical spectrometry to Trelys Venture Capital in Columbia, South Carolina. Williamson saw a genuine entrepreneurial opportunity. He proposed writing a Small Business Innovation Research [SBIR] grant with Myrick to develop this idea. Myrick was too busy, but he was willing to arrange for Williamson to license the technology and run with it. On October 5, 2004, Williamson and his collaborator, Scott Means, signed a licensing agreement with the USC Research Foundation to develop Myrick's work commercially (Williamson 2006).

Busy times for Williamson and Means followed. Shortly after signing the license agreement, they received venture capital from Trelys. This allowed Williamson to quit his job to devote himself full-time to Ometric. Means provided $25 \%$ of his time on a consulting basis. They wrote two successful SBIR grants, and they established a deal with GlaxoSmithKline to develop an analytical system (Williamson 2006).

The company grew. John James, a Chemistry graduate from Clemson, was hired away from his job waiting tables at a local Columbia restaurant. John Blackburn, a chemical engineer acquaintance of Williamson in Charleston, South Carolina, joined the effort, and two of Myrick's recent PhDs, Ryan Priore and David Perkins, started work for Ometric. In February 2005, Ometric moved into space in the USC NanoCenter next door to Myrick's lab. Care was taken to keep USC and Ometric distinct. Ometric paid rent for the space in the NanoCenter and for the time spent using Myrick's equipment (Vogt 2006).

In April 2005, Walter Alessandrini joined Ometric as its Chief Executive Officer. Williamson knew Allessandrini through Trelys, in which Alessandrini was an investor. At the time Williamson approached Alessandrini to run Ometric, Alessandrini was retired from a previous successful entrepreneurial effort, Avanex. For many reasons, Allessandrini was a pivotal hire for Ometric. One key relationship that Allessandrini brought was a connection with Sequoia Venture Capital, whose success stories include Yahoo and Google. Sequoia had successfully invested in Allessandrini's Avanex (Sequoia Venture Capital 2008). This bit of history got Ometric in the door at Sequoia when the former came knocking for venture capital. They were successful, and, in the summer of 2005, they obtained substantial venture capital from Sequoia. This was Sequoia's first investment east of the Rockies (Williamson 2006).

Through the fall of 2005 and the early spring of 2006, Ometric pushed hard to prepare for a commercial "coming out" at the March 2006 "Pittcon," the major-30,000+ attendees-annual analytical instrumentation conference in the United States (Wright 1999). Ometric rented a large booth at Pittcon 2006. They prepared multiple demonstrations of their 
instrumentation, including an analysis of powder in a blender, a pill analysis, and a liquid demonstration (Williamson 2006). I discuss the Pittcon launch in greater detail toward the end of the paper.

As of this writing, Ometric continues to develop its market in the pharmaceutical industry. And Ometric is also developing analytical instrumentation for the food industry. Water content in dog food kibble turns out to be critically important. In late 2006, Ometric left their space in the NanoCenter for better quarters elsewhere in Columbia. Myrick continues to serve as the Chief Technical Officer but also spends academic time on-campus. While nothing is certain, Ometric appears to have a bright future. This intellectual property is out of the lab and in the marketplace (Williamson 2006).

\section{Perfect Pills}

A typical pill is a mixture of active and inactive ingredients blended together and formed into an easily carried and ingested "button" or "seed." Blending is not perfect, and variation can occur in the percentages of ingredients in individual pills. Ometric instrumentation allows each pill to be non-destructively analyzed.

An engineered reality is a constructed reality controlled in selected respects. Control is a very slippery concept, and we can begin to appreciate how slippery it is by reflecting on Ometric's contribution to pharmaceutical manufacture. One might think-indeed as someone who relies on prescriptions, I certainly hope-that pills that claim to contain $\mathrm{X} \%$ active ingredient and $\mathrm{Y} \%$ other stuff actually contain these materials in these ratios. But how can we be sure? Previously, a manufacturer would sample a batch and analyze the pills-destructively-for contents. A bad batch would be scrapped. Careful statistical analysis can provide a high degree of confidence, but it is "statistical," which is to say, averaged over the long run. Ometric instrumentation allows for non-destructive examination of each pill. Individual pills that don't meet specifications can be scrapped individually, although, as emerges below, Ometric's approach is itself fully statistical in nature. The result should provide savings for the manufacturer-scrapping individual pills is more cost-effective than scrapping whole batches-and provide better quality control, down to the level of the individual pill.

"Control" in the engineering of reality requires identifying the variables to be controlled, a method for assessing success, and parameters for what constitutes success. Each of these aspects of control allow for a kind of slippage between a naïve fantasy of complete control-whatever that might mean-and what we actually achieve as we engineer reality. With Ometric's instrumentation one establishes ahead of time which compounds one 
wants information about. The instrument is not a "universal analyzer." In most situations, this is not a problem. A manufacturer will know which compounds need to be controlled in manufacturing a particular kind of pill. What the instrument will not do is tell us if something else, something unexpected and not controlled for, somehow got into the mix. Quality control of this sort already expects-"requires"-a well-understood and controlled process, in which only a few materials need to be measured. Here is a specific example of how precision begets more precision. Without prior control over the materials to be tested, Ometric would not be able to add further control.

\section{Perfect People}

I cannot pass this close to the idea we have of using pills to solve human ailments without comment. We are engineering a new relationship with our bodies, one in which many physical and mental problems are solved by pill. Consider asthma. In the eighteenth century, asthma was an unpleasant but rarely fatal disease. There was little to do beyond living through an asthma attack. Now we have an arsenal of pharmaceuticals, and many people can live with asthma without suffering. Of course, some of the medications have side-effects, and one must balance the desired effects of any pharmaceutical approach with its undesired effects.

More controversially, we have pills to deal with a variety of mental disorders. In many cases, we can avoid certain extremes of feeling. Grief, shock, lethargy, inability to concentrate-all can be blunted or eliminated by drugs. There is much of importance to say about these changes. ${ }^{1}$ Here I have two observations.

First, developing tools that provide control over our physical and mental symptoms changes our relationship to our bodies-which we now view as vessels to be perfected-and our understanding of what being human entails. Some people seriously write of "curing aging" as if mortality itself were not a fundamental aspect of being human. Is overwhelming grief at the loss of a loved one a fundamental part of being human? A nineteenth-century Romantic likely would say "yes." But now we can control these "fundamental aspects." By "fundamental aspect," I don't mean "biological aspect." I mean a property that plays a central role in structuring our personal and social worlds. Engineering this reality is not just making a better (by whose light?) reality for humans. It is redefining what it is to be human, period.

My second observation concerns the role of design in engineering reality. I take a drug designed to relieve the symptoms of my asthma. My

${ }^{1}$ See Crews (2007) for a discussion of some of these issues. 
nephew, when younger, took Ritalin to help rein in his Attention Deficit Hyperactivity Disorder. But now I am aware that some significant number of students take Ritalin to improve their scores on standardized academic tests, e.g., the SAT. Ritalin-it appears-enhances our abilities on such tests (Zernike 2005). This was not a designed feature of the drug, but a "side-effect" that for some has become the main desired effect. Designers may wish that they could control use, but users can have different ideas. In an important sense, design becomes distributed as downstream users invent new uses for a given constructed-engineered-part of the world.

Examining in any more detail the vexed question of pharmaceutical control of human mental states would take us too far from the primary focus of the paper, which is tied to Ometric's precision control in spectrometry. I turn back to that now.

\section{SUPERIOR SPECTROMETRY}

The basic principle that lies behind spectrometric analysis is that each element and compound interacts with light-or the electromagnetic spectrum more generally-in a unique way. One can use these interactions with light to identify elements and compounds. The instrumentation can be both expensive and, relatively speaking, not very rugged. Also, typically, spectrometric analysis has been done-destructively-on samples taken from a batch. It has not generally been possible to analyze each unit in production. Ometric provides solutions to these problems, and it does so in a way that is revealing about quality control.

Roughly speaking, a spectrometer first engages a sample for analysis with light. For instance, a sample in solution may have light transmitted through it. Depending on the composition of the sample, some wavelengths of light will be absorbed by the sample and some will pass through. By taking the resulting light and separating it into its component wavelengths, the way a prism separates white light into rainbow colors, and then measuring what wavelengths of light are present after interaction with the sample, an analyst can identify the compounds in the sample. Light separation requires delicate control of the optical pathway, which is one reason spectrometric equipment is not so rugged. This increases cost and makes it difficult to include spectrometric instrumentation in a factory/production setting.

Ometric instrumentation solves these problems by taking a lesson from statistical methods that were developed for social and cognitive analysis. As part of trying to understand and measure human cognitive abilities, "psychometricians" developed a wide variety of tests to measure various aspects of human cognitive functioning. By giving these diverse tests to many people, researchers could gather a large amount of 
data suitable for simultaneous analysis. An examination of the pattern of correlations between the various tests allowed psychometricians to construct measures that combined results from the multiple administered tests in a way that retained nearly all of the information from the administered tests but which used fewer dimensions (Baird 1987; Baird 1992; Jensen 1980). For example, a battery of twenty cognitive tests might be administered to a large population of test subjects. This analytical technique could allow nearly all of the information from these twenty tests to be captured in a small number (say three or fewer) "principal components." Thus, three dimensions or fewer, constructed from weighted combinations of the original twenty tests-or dimensions-capture nearly all of the information in the original twenty tests.

In the psychometric world, this technique and others like it led immediately to the idea that the constructed "principal components" are actual representations of the fundamental underlying human cognitive capacities, which any actual test only imperfectly measures (Block and Dworkin 1976; Eysenck and Kamin 1981; Jenson 1980). From both philosophical and psychological perspectives-not to mention the perspective of all of us who work with institutions that classify people according to measured cognitive abilities, e.g. universities-the question of the "realism" of the constructed principal components is important, interesting, and rather more subtle than my quick presentation here might suggest. However, we can put these questions aside when considering the use of these techniques in chemical analysis.

"Chemometric analyses" can be developed in fairly precise analogy to psychometric principal components analyses. The statistical methods are essentially identical, but the sources of the data put to statistical analysis are spectrometric instead of psychometric. In place of human subjects, we have samples of the material about which compositional information is sought. These could be samples taken from a batch of manufactured pharmaceuticals-a sample of pills. In place of different cognitive tests, we have measurements of how these samples respond at different wavelength bands to spectrometric analysis. By then analyzing the pattern of correlations between spectrometric responses of the samples at these different wavelengths bands, a chemical analyst employing these statistical techniques-a "chemometrician"-can construct principal components for the spectrometric analysis of these pharmaceuticals.

As with their psychological counterparts, these principal components are functions of the tested components-that is, of the responses of the pharmaceuticals at various wavelength bands. This is expressed mathematically by representing the value of a given pharmaceutical's principal component (or components, if more than one), PC, as a weighted 
linear combination of the values at the measured wavelength bands, $\mathrm{WL}_{i}$ :

$$
\mathbf{P C}=\left(\alpha_{1} \times \mathrm{WL}_{1}\right)+\left(\alpha_{2} \times \mathrm{WL}_{2}\right)+\ldots+\left(\alpha_{n} \times \mathrm{WL}_{n}\right) .
$$

In practice, this result has a very useful consequence. Instead of using a prism, grating, or other method to disperse light into different wavelength bands after interaction with the sample and then measuring the intensity at each of these wavelength bands, one can filter the light such that the relative amount of light passing through the filter at a given wavelength band is proportional to that band's weight in the principal component analysis. The entire set of weights determined by the principal component analysis $\left(\alpha_{1}, \alpha_{2}, \ldots \alpha_{n}\right)$ can be used to direct the construction of a light filter for all wavelength bands. One need only measure the resulting intensity of this single filtered light. This one measurement of light intensity will contain almost all of the information in the multiple measurements at multiple wavelength bands. This is the lesson of principal component analysis applied chemically.

Practically, this procedure drastically simplifies the instrumentation required for analysis. The light filter is the key part, and it, along with the rest of the parts necessary, can be made much more cheaply and much more sturdily than standard spectrometric instrumentation. All of the optical complexities behind analyzing these materials can be reduced to a custom-designed light filter and a single measurement of intensity.

This simplification of the required instrumentation does come at a cost. The filters used are customized for one specific analytical question. They allow one analytical question to be answered very efficiently. We can see in the functioning of Ometric instrumentation essential aspects of quality control. There are several things to notice about Ometric's approach. Here I briefly mention three.

It is principal components, not principle components. Perhaps the most curious aspect of principal components analysis and other similar methods is that the "components" that are constructed-or are they "uncovered"?-are found simply from an analysis of correlations between multiple tests. In Ometric's case, we have intensity outcomes in multiple wavelength bands. By testing many samples from the production situation Ometric instrumentation is being designed for, Ometric observes correlations between wavelength bands. These correlations are amenable to principal components analysis and the resulting reduction in dimensionality. Properly weighted, a single measurement of filtered light will contain nearly all of the same information as multiple wavelength band measurements. This result is found empirically. It is not deduced from first principles about how the materials in question should interact with light of the various wavelengths involved. 
The question of the "realism" of this constructed intensity measurement is not as pressing in the spectrometric context as it is in the psychometric context. There is little to question about the reality of wavelength intensities, and we have good general theoretical reason-and very long empirical practice-to justify the connection between spectrometrically-ascertained light intensities and chemical composition. Principal components analysis allows us to determine empirically a useful combination of wavelength intensities for a specific analytical question. But the fact remains that there is no specific theoretical justification for a specific weighting of light intensities in a given analytical situation. There is only the empirical work that directs the construction of a specific Ometric filter for a given application.

The reality to which Ometric instrumentation is applied is already a highly controlled reality. The specific production context in which Ometric's instrumentation might be used provides both a general theoretical backdrop-what kind of pharmaceutical synthesis is being examined, what materials are involved, in what kinds of states?-and essential empirical information. The latter is derived from multiple samples taken, spectrometrically measured, and subjected to principal components analysis. This method prompts sensible and largely uncontroversial answers to the key questions necessary for engineering reality: what specific variables do we need information about? What important elements and/or compounds in the particular synthesis are involved? What metric is appropriate to measure these variables? What filtered light intensity, deduced from a principal components analysis of data taken from samples from the synthesis, is needed? What will constitute acceptable outcomes? Only with this last question do further concerns arise. For various reasons, tolerances are more relaxed with dog food than pharmaceuticals, and the setting of tolerances is in part a matter for the market but also in part a matter of regulatory control. Generally speaking, though, precision begets better precision at each point: identification of variables, establishing metrics, and setting parameters.

As above, the key point here is that we only examine a very limited portion of the reality being engineered. In the contexts in which Ometric instrumentation is likely be useful, we have good reason to want to control the specific variables that Ometric instrumentation allows us to control. This is less the case as one moves away from the more carefully-controlled situations that one finds with chemical synthesis. More on this below.

Finally, I cannot leave this discussion without pointing out how Ometric instrumentation is a beautiful example of material knowledge (Baird 2004). This is most clearly seen in the filters that are customized for each application. These filters are material instantiations of a principal 
components analysis. There is a direct relationship between the relative weights $\left(\alpha_{1}, \alpha_{2}, \ldots, \alpha_{n}\right)$ that are the fundamental result of a principal components analysis and the material operation of the light filter. The instrument constitutes the knowledge developed statistically by principal components analysis.

What is perhaps even more interesting is how this material knowledge can be put to use in a decision making sense. By establishing boundaries on the acceptable values of the measured light intensities, Ometric instrumentation can directly implement quality control by rejecting results that are out of bounds. This is a key opportunity-and a key risk-provided by material knowledge: we can circumvent human decision-making in each instance by having the instrumentation take the measurements and act on the results.

\section{MAXIMIZING THE MARKET}

No matter how good a new invention is, it won't change the world if no one knows of it and no one buys it and uses it. While Ometric had negotiated a few early sales, their financial survival and the survival of their technology depended on and still depend on much more widespread adoption. This raised various issues for Ometric, but two were paramount in early 2006. Ometric had to inform potential users of their innovations, and they had to demonstrate the value of their product to potential purchasers. In short, they had to market their product. Ometric chose the Pittsburgh Conference or "Pittcon" as the first site to attack these issues.

Pittcon started in Pittsburgh in 1950. It has become the major event for analytical instrumentation. Over 30,000 people attend; there are more than 2,000 academic presentations and more than 1,000 instrument companies displaying their wares. While still called "Pittcon," the conference is too big to meet in Pittsburgh and typically meets in Orlando, Florida (Wright 1999).

Ometric went in heavy. Not content to rent a small display booth in the massive Orlando Convention Center, Ometric rented a larger "corner site" and built significant signage and a display structure to draw attention (Ometric Corporation 2008; see Figure 1). It would be easy for a company to get lost among the hundreds of instrument vendors unless it made a major effort to increase its visibility. Ometric hired local actors to stage faux demonstrations in front of the Convention Center. Chanting "We want real time," the demonstrators marched around with placards and slogans such as "I Want Control Right Now!" and "Control Freaks Unite!". Andrew Sorensen, President of the University of South Carolina, made an appearance, again in a concerted effort to gain visibility and traction for Ometric's product.

At their booth, Ometric personnel ran various demonstrations 


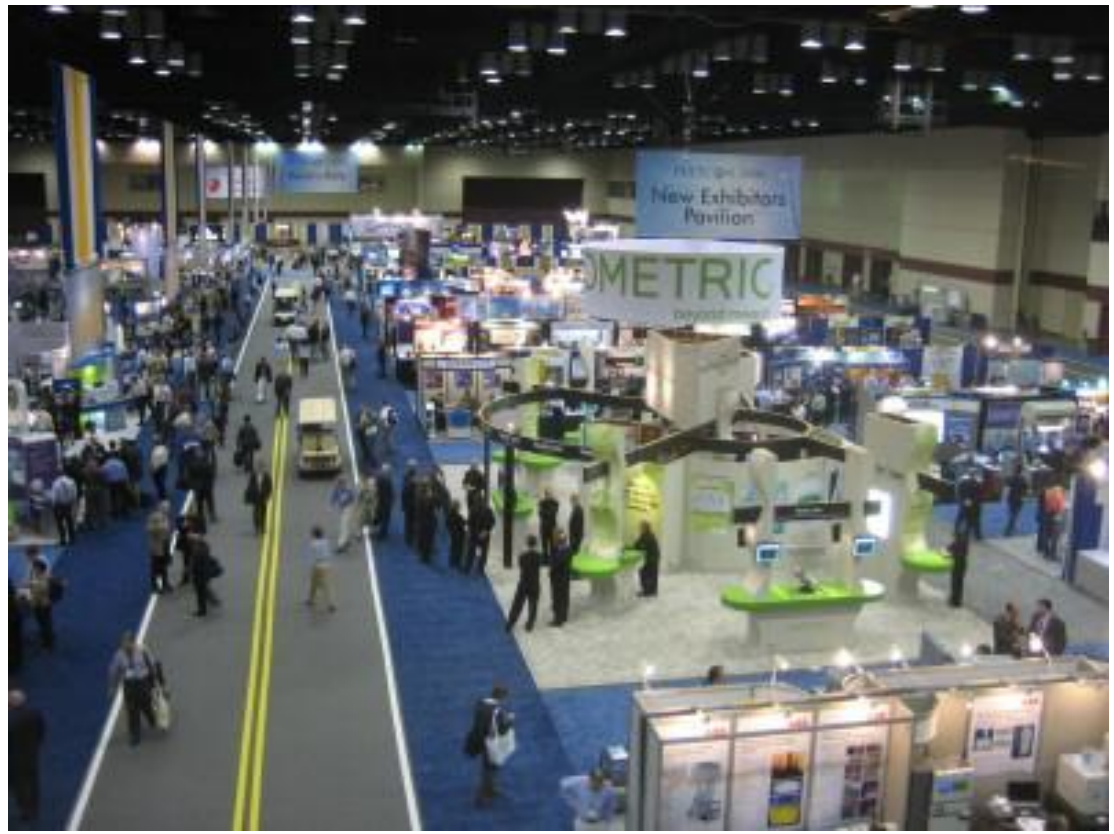

Figure 1. Ometric Booth at Pittcon 2006 (Ometric Corporation 2008).

of Ometric instrumentation. Pills were analyzed non-destructively, one-at-a-time, and quickly. Powders were analyzed, as were mixes. Pittcon connected Ometric with various important groups. Of course, analytical spectroscopists were interested, but Ometric also had talks with industries other than the pharmaceutical industry. In-line, real-time process control is important in the food industry as well.

Ometric went to Pittcon with the aim of hooking the prescription end of the pharmaceutical industry. They found more interest in the over-the-counter end of the industry. Here, margins are much smaller, and the potential savings advantage by scrapping individually defective pills instead of whole batches is more important. Another surprise was interest on the part of dog food manufacturers. Water content in dog food kibble is a critical variable, and Ometric's instrumentation provides a potentially very appealing way to control this variable.

There is an important point here. To be successful, an innovation has to add enough value to offset the cost of changing the way business is done. Tight margins turned out to be good for Ometric because cost savings are more critical than in cases where the margins are large. In the latter situation, the cost savings made possible by Ometric's instrumentation would not be significant in the overall competitive environment.

This is the reality that confronts Ometric in their efforts to successfully launch their product. This is yet another critically important sense of 
"engineering realities." Any newly engineered product has to survive in a competitive market. Survival requires adding enough value and there being sufficient awareness of this on the part of potential buyers. This is not a matter of "pure competition," for all of the various industries to which Ometric has sought to sell their instrumentation to are regulated in one way or another. State regulation, existing capital, human investment-what might be called capital and human investment-and improved marginal value all contribute to the reality facing Ometric and more generally any new innovation.

\section{BY WAY OF A CONCLUSION}

Precision begets better precision. This is manifestly part of Ometric's story. In order for Ometric instrumentation to be useful, the manufacturing process has already to be tightly structured and controlled. In order for the output of Ometric instrumentation to be accurate, the collection of chemical entities involved in the process has to be within the range used originally to develop parameters for the relative weightings for the wavelength bands in the optical filter. If the materials differ or if the amounts are radically at variance with those in the original samples, the light intensity after the light filter will not be an accurate measurement of the concentration of the chemical material in question. On the other hand, when the processing conditions do match those used in calibrating the light filter, Ometric instrumentation provides an accurate and economical means to make desired measurements.

Cost considerations are central. Ometric instrumentation does not provide a means to measure something previously immeasurable. Instead, it provides a means to make measurements that standard spectrometric instrumentation could already accomplish. But it can make these measurements non-destructively while the materials in question are being processed. Ometric's tag line captures this advantage: "Real-time, In-line." Furthermore, manufacturing companies will adopt Ometric instrumentation only if it provides needed information more economically than established approaches.

These two aspects of quality control-precision begets better precision, and cost considerations matter-interact. Modifications to a manufacturing process controlled by Ometric instrumentation require developing a new light filter, and this adds cost. Roughly put, precision quality control digs an economic rut, an engineering reality that is not metaphysically necessary but that can be costly to resist.

The engineering realities that result from this interaction are of less concern in contexts in which we have substantial understanding and control of the important variables involved in the process. This is true of 
contexts in which Ometric instrumentation is likely to be used. Moving away from such contexts exposes some of the issues and limitations of engineering reality. The point can be made with three examples.

In August 1854, London suffered a cholera outbreak in a small but densely populated area, "The Golden Square" east of Regent Street and south of Great Marlborough Street. Hundreds of people contracted and died from cholera. A significant consequence was that a local doctor, John Snow, was able to trace the source of the disease to a single water pump in the district. When the pump handle was removed, the epidemic abated, and subsequent work was able to show how the water at this pump was polluted by the waste of cholera sufferers in the area (Johnson 2006). While in hindsight Snow was able to tie cholera transmission to water, this was not the prevalent theory at the time, and Snow encountered significant resistance to his theory that the disease was water-borne. Prominent physicians and public health officials believed that cholera was communicated by "bad air" or "miasma." While Snow was carefully tracing where cholera victims got their water, the president of the national Board of Health, Benjamin Hall, formed a committee to investigate the outbreak. He gave the committee instructions for what research to carry out to localize the source of disease. Of fifty specific "variables" on which Hall sought data, only two concern water. Nearly all concern air and odour (Johnson $2006,165)$. Hall's committee laid the blame for the outbreak on unhealthful air. Despite the specific data accumulated by Snow and others, the water transmission theory was rejected.

While there is much of interest in this episode in the history of medicine and public health, the main point I want to highlight is how Hall's investigation prejudged the mechanism behind cholera transmission. Hall got "objective data," but the questions to which he sought answers ignored the importance of water as a possible means of transmission. The variables one chooses to examine matter.

More recently, a news story on National Public Radio exposed concerns about "treating the numbers" (Knox 2008). Vytorin is a combination of two cholesterol-lowering agents, and there is good evidence to show that it does lower cholesterol. But while the drug successfully lowers cholesterol to target ranges, new studies show that it does not reduce the amount of plaque in major arteries. Cholesterol level has been taken to be a primary variable to measure to control for heart disease. But it is a single datum from a very complex process. Dr. Steve Atlas of Massachusetts General Hospital was surprised by the divergence between cholesterol numbers and plaque, noting, "It's a big deal because it reminds us of something that we often forget: the number isn't the outcome. And this raises concerns that just lowering the number 
doesn't get you where you want to be" (Knox 2008). This case also reminds us of the epistemic distance between the data one acquires and the reality one is trying to engineer.

SAT tests and other high-stakes measures of academic qualifications for university admission provide further evidence of the interaction between the two readings of my title. These cognitive tests establish variables and metrics for academic ability, and it is worth keeping in mind that these are exactly the contexts for which the statistical techniques that Ometric instrumentation employs were developed. Universities establish parameters for admission (Lemann 1999). The process feeds back on itself, with curricula now routinely structured to help students improve their test scores. We teach to the test. Academic reality is moulded by our methods for measuring academic ability. I have little doubt that the SAT captures elements of academic ability. It is, however, one datum from a very complex reality. As in the case of Ometric quality control, the SAT is cost-effective. Reading 16,000 applications (at the University of South Carolina) would be a very daunting task without something like the SAT.

My conclusion follows the bifocal nature of the paper as a whole. On the one hand, Ometric provides an interesting case study of developing concepts of quality control and of how these concepts can be employed to engineer a reality. Furthermore, the reality that Ometric instrumentation has to enter in order to be commercially successful makes clear how cost considerations are central. On the other hand, I am concerned about potential abuses of these methods when the simple numerical measures they employ-and must employ for cost considerations-do not adequately and accurately describe the more complex reality that is their target. The epistemic distance between an engineered reality and the broader reality being corralled is significant. Furthermore, as we use these measures we shift reality. An engineered reality is no less real for the distance between it and the broader reality from which it is developed. Teaching to the test is real, and the academic reality that results is real-and, unfortunately, it is a diminished reality compared to the rich academic world from which it is fashioned.

\author{
DAVIS BAIRD \\ Office of Academic Affairs \\ Clark University \\ 950 Main Street \\ Worcester, MA, 01610 \\ (ph) 508-793-7673 \\ dbaird@clarku.edu
}




\section{REFERENCES}

Baird, Davis. 1987. Exploratory Factor Analysis: Instruments and the Logic of Discovery. British Journal for the Philosophy of Science 38: 319-37.

Baird, Davis. 1992. Inductive Logic: Probability and Statistics. Englewood Cliffs, $\mathrm{NJ}$ : Prentice Hall.

Baird, Davis. 2004. Thing Knowledge: A Philosophy of Scientific Instruments. Berkeley, CA: University of California Press.

Block, Nod, and Gerald Dworkin. 1976. The IQ Controversy: Critical Readings. New York: Pantheon Books.

Crews, Frederick. 2007. Talking Back to Prozac. New York Review of Books 5, no. 19 (December 6).

Eysenck, Hans J., and Leon Kamin. 1981. The Intelligence Controversy. New York: John Wiley and Sons.

Jensen, Arthur. 1980. Bias in Mental Testing. New York: Free Press.

Johnson, Steven. 2006. The Ghost Map: The Story of London's Most Terrifying Epidemic and How It Changed Science, Cities, and the Modern World. New York: Riverhead Books.

Knox, Robert. 2008. Doctors' 'Treat the Numbers' Approach Challenged. National Public Radio. www.npr.org/templates/story/ story.php?storyld $=88650768$.

Lemann, Nicholas. 1999. The Big Test: The Secret History of the American Meritocracy. New York: Farrar, Straus \& Giroux.

Myrick, Michael, Matthew Nelson, and Karl Booksh. 2001. Optical computational system. U. S. Patent 6,198,531 B1, filed July 11, 1997, and issued March 6, 2001.

Myrick, Michael. 2004. Interview with the author, December 15, 2004.

nanoScience and Technology Studies Group. 2008. www.nano.sc.edu/research/societalinteractionswithnanotechnology.aspx.

Ometric Corporation. 2008. Ometric Spectrlnline. www.ometric.com.

Sequoia Venture Capital. 2008. Venture Capital Funding - Venture Capitalists Sequoia Capital. www.sequoiacap.com.

Toumey, Chris, and Davis Baird. 2008. Nanoliteracy: Nurturing Understandings of Nanotechnology and Societal Interactions with Nanotech. In Nanoscale Science and Engineering Education, eds. Aldrin Sweeney and Sudipta Seal, 577-89. New York: American Scientific Publishers.

Vogt, Thomas. 2006. Interview by author, August 6, 2006.

Williamson, Jason. 2006. Interview by author, August 29, 2006.

Wright, Judith. 1999. Vision, Venture and Volunteers: Fifty Years of History of the Pittsburgh Conference on Analytical Chemistry and Applied Spectroscopy. Philadelphia: Chemical Heritage Foundation.

Zernike, Kate. 2005. The Difference Between Steroids and Ritalin is... Week in Review New York Times. March 20. 